DOI: https://doi.org/10.17648/2238-037X-trabedu-v28n3-13540

\title{
A FORMAÇÃO DE PROFESSORES DO PRIMEIRO CICLO EM PORTUGAL ${ }^{1}$
}

\author{
The formation of the first cycle teachers in Portugal
}

RINCON, Claudia G. Vasconcelos ${ }^{2}$ DEVECHI, Catia Piccolo Viero ${ }^{3}$

\section{RESUMo}

O artigo expõe a reorganização e a nova estrutura curricular dos cursos de formação de professores para o 1ํ Ciclo de Ensino Básico em Portugal, após a implementação do Processo de Bolonha, tendo como objetivos apresentar as mudanças concretizadas e fomentar reflexões críticas em relação ao tema. $\mathrm{O}$ estudo fundamenta-se na pesquisa qualitativa e adota um percurso metodológico baseado nas pesquisas bibliográfica e documental. Buscamos refletir sobre a formação docente a partir do percurso curricular em vigor e da perspectiva de autores portugueses sobre as alterações curriculares e paradigmáticas trazidas pelo pacto. Percebemos a consolidação das orientações de Bolonha sob divergências de opiniões acerca de suas vantagens e desvantagens na formação inicial docente para os anos iniciais da Educação Básica.

Palavras-chave: Formação inicial de professores. Educação anos iniciais. Processo de Bolonha.

\section{ABstract}

This article presents the reorganization and the new curricular structure of the courses on the formation of teachers for the First Cycle of Basic Education in Portugal, after the implementation of the Bologna Process, aiming to present the realized changes in order to promote critic reflections in relation to the theme. This is based on qualitative research and adopts a methodologic perspective stablished on bibliographic and documental research. The teacher training was analyzed considering the actual curricular course and Portuguese authors' perspective on the curricular changes and paradigms raised up by the pact. We noticed the Bologna guidelines consolidation under discussion on the advantages and drawbacks on the initial teacher formation for the first years of elementary school.

Keywords: Initial teachers formation. Elementary education. Bologna process.

\footnotetext{
${ }^{1}$ O texto é resultante de pesquisa sobre a formação de professores no $1^{\circ}$ Ciclo de Ensino Básico em Portugal após a implementação do Processo de Bolonha.

${ }^{2}$ Mestranda em Educação pela Universidade de Brasília, Graduação em Pedagogia pela Universidade de Brasilia. Professora da

Secretaria de Estado de Educação do Distrito Federal. E-mail: cacaurincon@yahoo.com.br.

${ }^{3}$ Doutora em Educação. Professora associada da Faculdade de Educação da Universidade de Brasilia e coordenadora do Grupo de Estudos sobre Filosofia da Educação e Formação de Professores (GEFFOP). E-mail: catiaviero@gmail.com.
}

Trabalho \& Educação | v.28 | n.3 | p.51-67 | set-dez | 2019 


\section{CONSIDERAÇõES INICIAIS}

Com o objetivo de atender as demandas da sociedade, melhorar a empregabilidade e a mobilidade do cidadão europeu, bem como a competitividade internacional (PEREIRA, 2011), a política educacional trazida pelo Processo de Bolonha incentivou importantes reformas no ensino superior europeu como mudanças na organização, no sistema de créditos e principalmente, no seu enfoque paradigmático.

Portugal assinou a Declaração de Bolonha, em 1999, assumindo o compromisso de acatar as políticas educacionais estabelecidas. Contudo, a implementação dessas políticas só teve início no país em 2005 com o Decreto-Lei no 42, que incorporou os acordos internacionais para a criação do Espaço Europeu de Ensino Superior até 2010. A reestruturação dos cursos universitários colocou em prática a arquitetura de três ciclos de estudos, isto é, a implementação de currículos com estudos sequenciais em diferentes graus: licenciatura, mestrado e doutorado.

Assim aconteceu também como a formação do professor do primeiro ciclo da escola básica. Para Martins (2006), autor português, houve um atraso na reorganização da formação de professores tendo em vista que os cursos vinham sendo oferecidos tanto em universidades como institutos politécnicos, sendo necessário repensar a formação a partir dos mesmos critérios e de forma articulada. Os dois sistemas de ensino superior apresentam objetivos e funções diferenciadas, uma vez que o universitário alia ensino e investigação de modo a oferecer uma formação científica e o superior politécnico volta-se para uma formação vocacional e técnica. Galeno (2016), outro autor português, explica que as diferenças alcançam a organização institucional dos sistemas, pois as universidades podem oferecer os três ciclos de formação (licenciatura, mestrado e doutorado), além de realizar provas de agregação (mais alto reconhecimento profissional da carreira acadêmica), e os institutos politécnicos estão limitados aos dois primeiros ciclos de formação (licenciatura e mestrado).

O presente artigo busca apresentar como os cursos de formação para docência no $1^{\circ}$ Ciclo de Ensino Básico (CEB) têm se organizado na universidade e no politécnico e quais defesas têm sido feitas por educadores portugueses diante da reforma consequente do Processo de Bolonha. $\mathrm{O}$ estudo baseou-se numa abordagem hermenêutica, bibliográfica e documental como percurso metodológico para compreender os pontos positivos e negativos das mudanças curriculares para formação inicial do docente para os primeiros anos de escolarização da Educação Básica em Portugal. O texto está organizado em duas partes: apresentação do percurso curricular adotado por Portugal para formação inicial docente para anos iniciais após a reestruturação do ensino superior incentivado por Bolonha; exposição das percepções de autores portugueses sobre formação docente atual.

\section{Percurso CurRicular da formação de Professores dos anOS INICIAIS}

Após a entrada do Decreto-Lei no 74/2006, a legislação acerca da habilitação para carreira docente passou por mudanças significativas. O regime jurídico de habilitação profissional para docência na educação pré-escolar e nos ensinos básico e secundário foi estabelecido pelo Decreto-Lei $n^{\circ}$ 43/2007, posteriormente alterado pelo Decreto-Lei no 79/2014. A habilitação profissional passou a ser indispensável para o exercício da docência e o Decreto-Lei no 79/2014 diz que "têm habilitação profissional para a 
docência em cada grupo de recrutamento os titulares do grau de mestre na especialidade correspondente constante do anexo ao presente decreto-lei, que dele faz parte integrante" (PORTUGAL, 2014, p. 2821).

O regime em vigor prevê um modelo de formação docente organizado em dois ciclos de estudos: licenciatura ( $1^{\circ}$ ciclo) e mestrado $\left(2^{\circ}\right.$ ciclo) e determina que a habilitação para docência no $1^{\circ}$ Ciclo do Ensino Básico em Portugal depende de licenciatura em Educação Básica e mestrado em uma das quatro possibilidades: em Ensino do 1ํ Ciclo do Ensino Básico; em Educação Pré-Escolar e 1ํㅡㄹ Ciclo do Ensino Básico; em Ensino do 1ํㅡㄹ Ciclo e Ensino de Português e História e Geografia no 2ํㅡㄹ Ciclo do Ensino Básico; ou em Ensino do 1ํㅡㄹ Ciclo e Ensino de Matemática e Ciência Naturais no $2^{\circ}$ Ciclo do Ensino Básico.

Quadro 1- Habilitação para docência no 10 Ciclo do Ensino Básico

\begin{tabular}{|c|c|c|c|}
\hline Licenciatura & Mestrado & Especialidades de ensino & Habilitação \\
\hline \multirow{3}{*}{$\begin{array}{l}\text { Educação } \\
\text { Básica }\end{array}$} & $\begin{array}{l}\text { Ensino do } 1^{\circ} \text { e Ciclo do } \\
\text { Ensino Básico }\end{array}$ & $\begin{array}{c}\text { Todas as áreas do } 1^{\circ} \text { Ciclo do } \\
\text { Ensino Básico }\end{array}$ & $\begin{array}{l}\text { Professor do } 1^{\circ} \text { Ciclo } \\
\text { do Ensino Básico }\end{array}$ \\
\hline & $\begin{array}{l}\text { Ensino pré-escolar e } \\
\text { Ensino do } \text { 10 }^{\circ} \text { Ciclo do } \\
\text { Ensino Básico }\end{array}$ & $\begin{array}{l}\text { Educação pré-escolar e todas as } \\
\text { áreas do 1ํㅡiclo do Ensino Básico }\end{array}$ & $\begin{array}{c}\text { Professor da } \\
\text { educação pré-escolar } \\
\text { e do } 1^{\circ} \text { Ciclo do } \\
\text { Ensino Básico }\end{array}$ \\
\hline & $\begin{array}{l}\text { Ensino do } 1^{\circ} \text { e do } 2^{\circ} \\
\text { Ciclos do Ensino } \\
\text { Básico }\end{array}$ & $\begin{array}{l}\text { Todas as áreas do } 1^{\circ} \text { Ciclo do } \\
\text { Ensino Básico e as seguintes áreas } \\
\text { do } 2^{\circ} \text { Ciclo do Ensino Básico: } \\
\text { Português, História e Geografia de } \\
\text { Portugal ou Matemática e Ciências } \\
\text { da Natureza }\end{array}$ & $\begin{array}{c}\text { Professor do } 1^{\circ} \text { e do } \\
2^{\circ} \text { Ciclos do Ensino } \\
\text { Básico }\end{array}$ \\
\hline
\end{tabular}

Fonte: Elaborado pelas pesquisadoras. Almeida e Faria (2015), atualizado a partir do Decreto-Lei no $79 / 2104$.

De acordo com as autoras portuguesas Vieira e Damião (2013), a oferta diferenciada no mestrado possibilita uma ampliação na atuação docente, uma vez que o professor que pretende atuar no 1ํ Ciclo do Ensino Básico também poderá estar habilitado para atuar na Educação Infantil ou no $2^{\circ}$ Ciclo do Ensino Básico, dependendo da sua escolha dentre as especialidades no mestrado.

O Decreto-lei discorre também sobre as estruturas curriculares e estabelece a creditação dos ciclos de estudos referente ao grau de licenciado e mestre. A licenciatura em Educação Básica corresponde a 180 créditos e a creditação do mestrado varia de acordo com o domínio: 90 créditos no 1ํ Ciclo do Ensino Básico; 120

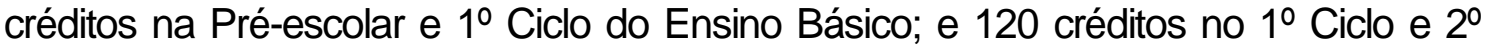
Ciclo (habilitações específicas) do Ensino Básico (PORTUGAL, 2014). Cabe à licenciatura assegurar a formação básica na área docente, e ao mestrado, garantir aprofundamento dos conhecimentos necessários à docência na formação acadêmica iniciada no $1^{\circ}$ ciclo (licenciatura). O documento determina, ainda, que compete ao $2^{\circ}$ ciclo de estudos (mestrado) "assegurar a formação educacional geral, a formação nas didáticas específicas da área da docência, a formação nas áreas cultural, social e ética e a iniciação à prática profissional, que culmina com a prática supervisionada." (PORTUGAL, 2014, p. 2819).

Os ciclos de estudos para a habilitação profissional são respaldados por componentes de formação que garantem o cumprimento das exigências da docência; formação educacional geral; formação cultural, social e ética; didáticas específicas e iniciação à prática educacional. No entanto, para que as instituições de educação superior possam 
oferecer a aquisição da habilitação docente, é necessária a celebração de protocolos de cooperação com escolas cooperantes para que desenvolvam atividades de iniciação à prática profissional, incluindo a prática de ensino supervisionada. A realização da cooperação institucional impôs algumas obrigações às instituições de educação superior, dentre elas a verificação, nas escolas cooperantes, de condições materiais e humanas necessárias à formação de qualidade, à participação ativa e articulada com a gestão educacional para o desenvolvimento da qualidade de ensino nas escolas e escolha do orientador cooperante, docente colaborador na formação (PORTUGAL, 2014).

Salienta-se a importância da docência na qualidade educacional e defende-se uma rigorosa preparação de educadores e professores, especialmente no que tange aos conhecimentos de matérias e didáticas, de forma a valorizar a profissão. De acordo com o decreto-lei, a qualidade do sistema de ensino está diretamente ligada ao aumento do nível da formação docente, indicando que quanto maior o grau de conhecimento do professor, maior será a autonomia e a segurança em seu desempenho em sala de aula e, portanto, na aprendizagem dos alunos. As unidades curriculares de docência ministradas na formação inicial de professores são consideradas fundamentais e não podem ser substituídas pela formação continuada, muito embora admita-se que essa também desempenhe papel educacional importante (PORTUGAL, 2014).

Com o objetivo de promover a melhora na formação do professor, o governo estabeleceu políticas educacionais que garantam nas escolas portuguesas os professores "mais bem preparados, mais bem treinados, mais vocacionados e mais motivados para desenvolver a nobre e exigente tarefa de ensinar" (PORTUGAL, 2014, p. 2820). Centrado nesse objetivo, regulamentou-se a Prova de Avaliação de Conhecimento e Capacidades, promovendo mudanças na formação contínua de docentes, aumentando a exigência na admissão em cursos de educação básica.

A formação dos professores da educação pré-escolar, básica e secundária acontece em estabelecimentos públicos e privados. No entanto, as Instituições de Ensino Superior (IES) públicas têm como foco a formação docente para 1ำ Ciclo do Ensino Básico. O Ministério da Educação de Portugal, por meio da Direção-Geral de Estatísticas da Educação e Ciência (DGEEC), lista 19 IES públicas, das quais 13 são institutos politécnicos e 6 são universidades. Os ciclos de estudos para a formação docente para atuação no 1 ciclo são oferecidos por Escolas Superiores de Educação (ESE) vinculadas aos institutos politécnicos e por escolas ou institutos nas universidades.

Para oferecer a habilitação exigida para docência no $1^{\circ}$ Ciclo do Ensino Básico, tanto os institutos politécnicos quanto as universidades devem ofertar ciclos de estudos que tenham como base os currículos e as matrizes curriculares da educação básica, as políticas de educação e os princípios estabelecidos pela Lei no 49/2005 (PORTUGAL, 2014). Dentre os princípios educativos elencados, destacam-se as formações que proporcionem informação, método, técnica científica e pedagógica aos docentes para o exercício da profissão, que promovam a integração na preparação científicopedagógica e na articulação da teoria e prática, que incentivem posturas críticas e atuantes, que encorajem e promovam a inovação e a investigação voltadas para a prática educativa (PORTUGAL, 2005). Os ciclos de ensino devem incluir componentes de formação que se integrem com as exigências da atividade profissional e tenham 
objetivos diferenciados que, de forma integrada, visem à aquisição da habilitação para docência oferecida por ambos os estabelecimentos de ensino superior nos dois ciclos de formação (PORTUGAL, 2014).

A formação na área docente trata dos conteúdos e unidades curriculares necessárias para atuação profissional e tem como objetivo o fortalecimento da formação acadêmica. Tal componente está diretamente relacionada à formação em didáticas específicas, pois abrange os conhecimentos que se vinculam aos conteúdos e às unidades curriculares trabalhadas na área docente. Já a formação na área educacional geral refere-se a conhecimentos, habilidades e comportamentos fundamentais para que todos os docentes desempenhem sua função nos vários espaços escolares e na relação com a família e a comunidade. "As áreas da psicologia do desenvolvimento, dos processos cognitivos, designadamente os envolvidos na aprendizagem da leitura e da matemática elementar, do currículo e da avaliação, da escola como organização educativa" (PORTUGAL, 2014, p. 2821), dentre outros ramos, integram essa componente de formação.

A iniciação à prática docente profissional é composta por observação, colaboração e prática supervisionada em atividades de ensino, dentro e fora das salas de aula, nas instituições de educação. O propósito é propiciar aos futuros professores contato mais aproximado com as funções docentes, como, por exemplo, o planejamento, o ensino e a avaliação. Sendo concebida numa perspectiva formativa de desenvolvimento profissional que visa à aprendizagem, volta-se para articulação entre o conhecimento e a maneira de transmiti-lo, de forma a alcançar o melhor desempenho dos alunos. Para atingir seus objetivos, essa componente é realizada em grupos ou turmas dos diferentes níveis e ciclos de educação e ensino abrangidos pelo grupo de recrutamento 4 para o qual o ciclo de estudos prepara, devendo se necessário, realizarse em mais de um estabelecimento de educação de ensino, pertencente, ou não, ao mesmo agrupamento de escolas ou à mesma entidade titular, no caso do ensino particular ou cooperativo (PORTUGAL, 2014).

A realização dessa componente diretamente ligada à prática profissional acontece em diferentes níveis de ensino em razão da possibilidade de variadas formações para atuação docente na educação pré-escolar, no $1^{\circ}$ ou $2^{\circ}$ Ciclos do Ensino Básico. Caso o estudante esteja cursando mestrado em Educação Pré-Escolar e Ensino do $1^{\circ}$ Ciclo de Ensino Básico, por exemplo, deverá fazer a iniciação à prática docente em turmas da Educação Pré-Escolar e do 1ํㅡ Ciclo de Ensino Básico. A definição do grupo de recrutamento em que formação na prática docente acontecerá depende da especialidade de mestrado em que o estudante ingressou, como podemos perceber no recorte do quadro trazido na referida legislação.

\footnotetext{
${ }^{4}$ O grupo de recrutamento é mencionado pelo Decreto-lei no 79/2014 e se refere aos níveis de ensino para o qual o formado estará habilitado.
} 
Quadro 2- Especialidades do grau de mestre, requisitos mínimos de formação para ingresso de grupos de recrutamento

\begin{tabular}{|c|c|c|}
\hline $\begin{array}{l}\text { Especialidade do grau de } \\
\text { mestre }\end{array}$ & $\begin{array}{c}\text { Requisitos mínimos de formação } \\
\text { para o ingresso no ciclo de } \\
\text { estudos conducentes ao grau de } \\
\text { mestre }\end{array}$ & $\begin{array}{l}\text { Grupos de } \\
\text { recrutamento }\end{array}$ \\
\hline $\begin{array}{l}\text { Ensino do 1ํㅡㄹo de Ensino } \\
\text { Básico. }\end{array}$ & Licenciatura em Educação Básica & $\begin{array}{c}\text { 1 Ciclo do Ensino } \\
\text { Básico }\end{array}$ \\
\hline \multirow{2}{*}{$\begin{array}{l}\text { Educação Pré-Escolar e Ensino } \\
\text { do 1ํ Ciclo do Ensino Básico. }\end{array}$} & \multirow[b]{2}{*}{ Licenciatura em Educação Básica } & Pré-Escolar \\
\hline & & $\begin{array}{c}\text { 10 Ciclo do Ensino } \\
\text { Básico }\end{array}$ \\
\hline \multirow{2}{*}{$\begin{array}{l}\text { Ensino do } 1^{\circ} \text { Ciclo do Ensino } \\
\text { Básico e de Português e História } \\
\text { e Geografia de Portugal no } 2^{\circ} \\
\text { Ciclo do Ensino Básico. }\end{array}$} & \multirow[b]{2}{*}{ Licenciatura em Educação Básica } & $\begin{array}{c}\text { 1\% Ciclo do Ensino } \\
\text { Básico }\end{array}$ \\
\hline & & $\begin{array}{l}\text { Português e } \\
\text { Estudos } \\
\text { Sociais/História }\end{array}$ \\
\hline \multirow{2}{*}{$\begin{array}{l}\text { Ensino do } 1^{\circ} \text { Ciclo do Ensino } \\
\text { Básico e de Matemática e } \\
\text { Ciências Naturais no } 2^{\circ} \text { Ciclo do } \\
\text { Ensino Básico. }\end{array}$} & \multirow[b]{2}{*}{ Licenciatura em Educação Básica } & $\begin{array}{c}\text { 1 Ciclo do Ensino } \\
\text { Básico }\end{array}$ \\
\hline & & $\begin{array}{c}\text { Matemática e } \\
\text { Ciências da } \\
\text { Natureza }\end{array}$ \\
\hline
\end{tabular}

Fonte: Elaborado pelas pesquisadoras. Portugal (2014).

Já a formação na área cultural, social e ética tem como objetivo a sensibilização sobre questões da contemporaneidade e envolve os valores trazidos pela Constituição da República portuguesa: a expansão da cultura científica, artística e de humanidades para além das áreas de docência; a proximidade com a produção de dados e sua análise crítica; e a conscientização dos aspectos éticos e cívicos que compõem a atividade docente. No entanto, a legislação não atribuiu a essa componente um mínimo de créditos a serem desenvolvidos de forma isolada durante a formação docente, mas assegurou a sua realização no âmbito de todas as outras componentes (PORTUGAL, 2014).

A estrutura curricular do ciclo de estudos conducentes ao grau de licenciado em Educação Básica é composta por 180 créditos, distribuídos pelas componentes de formação. O Decreto-lei no 79/2014 destaca, nesse ciclo de estudos, a componente de "formação da área de docência", pois além de lhe conferir a maior quantidade de créditos, estabelece a quantidade mínima de créditos por unidade curricular que a integra. Na licenciatura, dos 125 créditos mínimos destinados a essa componente, pelo menos 30 são atribuídos as unidades curriculares: Português; Matemática; Ciências Naturais e História e Geografia de Portugal e expressões.

As estruturas curriculares dos mestrados variam em quantidade de créditos e na distribuição das componentes de formação de acordo com a especialidade cursada, conforme se verifica no Quadro 3. Quando se trata de uma única habilitação, o número de créditos do ciclo de estudo para o grau de mestre é de 90 créditos, mas quando a habilitação é dupla, a quantidade de créditos aumenta para 120. Dessa forma, o mestrado em 1ํㅡㄹ Ciclo do Ensino Básico tem duração de 3 semestres e os mestrados em Educação Pré-Escolar e 1ํ Ciclo do Ensino Básico e em 1ํ e 2ํㅡㄹ Ciclos do Ensino Básico, independente da habilitação para o $2^{\circ}$ ciclo, têm sua duração ampliada para 4 semestres (PORTUGAL, 2014). 
Quadro 3- Distribuição de créditos por componentes de formação

\begin{tabular}{|c|c|c|c|c|}
\hline \multirow[b]{3}{*}{$\begin{array}{l}\text { Componentes de } \\
\text { formação }\end{array}$} & \multicolumn{4}{|c|}{ Créditos } \\
\hline & Licenciatura & & Mestrados & \\
\hline & $\begin{array}{l}\text { Educação } \\
\text { Básica }\end{array}$ & $\begin{array}{c}\text { Ensino do } \\
\text { 1o Ciclo do } \\
\text { Ensino } \\
\text { Básico }\end{array}$ & $\begin{array}{c}\text { Educação } \\
\text { Pré-Escolar } \\
\text { e Ensino do } \\
\text { 10 Ciclo do } \\
\text { Ensino } \\
\text { Básico }\end{array}$ & $\begin{array}{c}\text { Ensino do } 1^{\circ} \\
\text { Ciclo do } \\
\text { Ensino Básico } \\
\text { e de Ensino de } \\
\text { Português e } \\
\text { História e } \\
\text { Geografia de } \\
\text { Portugal ou de } \\
\text { Matemática e } \\
\text { Ciências } \\
\text { Naturais no 2o } \\
\text { Ciclo do } \\
\text { Ensino Básico }\end{array}$ \\
\hline Área de docência & Mínimo de 125 & $\begin{array}{c}\text { Mínimo de } \\
18\end{array}$ & $\begin{array}{c}\text { Mínimo de } \\
18\end{array}$ & Mínimo de 27 \\
\hline Área educacional geral & Mínimo de 15 & Mínimo de 6 & Mínimo de 6 & Mínimo de 6 \\
\hline Didáticas específicas & Mínimo de 15 & $\begin{array}{c}\text { Mínimo de } \\
21\end{array}$ & $\begin{array}{l}\text { Mínimo de } \\
36\end{array}$ & Mínimo de 30 \\
\hline $\begin{array}{l}\text { Área cultural, social e } \\
\text { ética }\end{array}$ & * & $*$ & * & * \\
\hline $\begin{array}{l}\text { Iniciação à prática } \\
\text { profissional** }\end{array}$ & Mínimo de 15 & $\begin{array}{l}\text { Mínimo de } \\
32\end{array}$ & $\begin{array}{l}\text { Mínimo de } \\
48\end{array}$ & Mínimo de 48 \\
\hline
\end{tabular}

Fonte: Elaborado pelas pesquisadoras. Almeida e Faria (2015), atualizado a partir do Decreto-

Lei no 79/2104. * Componente de formação assegurada no âmbito das demais componentes

(PORTUGAL, 2014a). ${ }^{* *}$ Nos mestrados essa componente de formação recebe o nome de prática de ensino supervisionada.

Caso os graus de ensino estabeleçam o mínimo de créditos determinado pela legislação para cada componente de formação, restarão 10 créditos na licenciatura, 13 no mestrado em Ensino no 1ำ Ciclo do Ensino Básico, 12 no mestrado em Educação Pré-Escolar e Ensino do 1ํㅡㄹ Ciclo do Ensino Básico e 9 no mestrado em Ensino do $1^{\circ}$ Ciclo do Ensino Básico e de Ensino de Português e História e Geografia de Portugal ou de Matemática e Ciências Naturais no 2ํㅡㄹ Ciclo do Ensino Básico que poderão ser utilizados para assegurar a formação na área cultural, social e ética.

Ao ofertar mais de uma modalidade de mestrado, a instituição de educação superior pode oferecer, simultaneamente, aos estudantes de diferentes mestrados, a formação nas componentes da área educacional geral; da área cultural, social e ética, da área de docência e em parte da iniciação à prática profissional, desde que em turmas com tamanhos pedagogicamente aceitáveis (PORTUGAL, 2014).

A organização da formação docente para o Ensino do 1ํ Ciclo do Ensino Básico, apesar de seguir as determinações trazidas pela legislação em vigor, apresenta diversidades. Todas as universidades e os institutos politécnicos que formam esses profissionais oferecem licenciatura em Educação Básica, todavia, as especialidades dos mestrados variam de acordo com a instituição que, dentro da discricionariedade permitida pelo Decreto-lei no 79/2014, oferta uma, duas, três ou até quatro especialidades, podendo apresentar diferentes estruturas curriculares em cada uma delas.

A formação docente para o ensino do $1^{\circ}$ Ciclo do Ensino Básico tem como característica comum a presença do mestrado na especialidade Educação Pré-Escolar e Ensino do 1ํㅡㄹ Ciclo do Ensino Básico em todas as universidades, como retrata o 
Quadro 4. O mesmo não acontece nos institutos politécnicos, pois duas instituições politécnicas públicas não oferecem mestrado em Educação Pré-escolar e Ensino de $1^{\circ}$ Ciclo do Ensino Básico.

Quadro 4- Especialidades de mestrado oferecidas pelas Instituições Públicas de Educação Superior

\begin{tabular}{|c|c|c|}
\hline $\begin{array}{l}\text { Instituição de } \\
\text { educação superior } \\
\text { (IES) }\end{array}$ & Quantidade & Especialidades de mestrado \\
\hline \multirow{4}{*}{ Universidade } & 3 & $\begin{array}{l}\text { Educação Pré-Escolar e Ensino do 1ํㅡㄹ Ciclo do } \\
\text { Ensino Básico }\end{array}$ \\
\hline & \multirow{3}{*}{3} & $\begin{array}{l}\text { Educação Pré-Escolar e Ensino do 1ํㅡㄹ Ciclo do } \\
\text { Ensino Básico }\end{array}$ \\
\hline & & $\begin{array}{l}\text { Ensino do } 1^{\circ} \text { Ciclo do Ensino Básico e em Português } \\
\text { e História e Geografia no } 2^{\circ} \text { Ciclo do Ensino Básico }\end{array}$ \\
\hline & & $\begin{array}{l}\text { Ensino do } 1^{\circ} \text { Ciclo do Ensino Básico e em } \\
\text { Matemática e Ciências Naturais no } 2^{\circ} \text { Ciclo do } \\
\text { Ensino Básico }\end{array}$ \\
\hline \multirow{12}{*}{ Instituto Politécnico } & 2 & $\begin{array}{l}\text { Educação Pré-Escolar e Ensino do 1ํㅡㄹ Ciclo do } \\
\text { Ensino Básico }\end{array}$ \\
\hline & \multirow{3}{*}{7} & $\begin{array}{l}\text { Educação Pré-Escolar e Ensino do 1ํ Ciclo do } \\
\text { Ensino Básico }\end{array}$ \\
\hline & & $\begin{array}{l}\text { Ensino do } 1^{\circ} \text { Ciclo do Ensino Básico e em Português } \\
\text { e História e Geografia no } 2^{\circ} \text { Ciclo do Ensino Básico }\end{array}$ \\
\hline & & $\begin{array}{l}\text { Ensino do } 1^{\circ} \text { Ciclo do Ensino Básico e em } \\
\text { Matemática e Ciências Naturais no } 2^{\circ} \text { Ciclo do } \\
\text { Ensino Básico }\end{array}$ \\
\hline & \multirow[b]{2}{*}{2} & $\begin{array}{l}\text { Ensino do } 1^{\circ} \text { Ciclo do Ensino Básico e em Português } \\
\text { e História e Geografia no } 2^{\circ} \text { Ciclo do Ensino Básico }\end{array}$ \\
\hline & & $\begin{array}{l}\text { Ensino do } 1^{\circ} \text { Ciclo do Ensino Básico e em } \\
\text { Matemática e Ciências Naturais no } 2^{\circ} \text { Ciclo do } \\
\text { Ensino Básico }\end{array}$ \\
\hline & \multirow[b]{2}{*}{1} & $\begin{array}{l}\text { Educação Pré-Escolar e Ensino do } 1^{\circ} \text { Ciclo do } \\
\text { Ensino Básico }\end{array}$ \\
\hline & & $\begin{array}{l}\text { Ensino do } 1^{\circ} \text { Ciclo do Ensino Básico e em } \\
\text { Matemática e Ciências Naturais no } 2^{\circ} \text { Ciclo do } \\
\text { Ensino Básico }\end{array}$ \\
\hline & \multirow{4}{*}{1} & $\begin{array}{l}\text { Educação Pré-Escolar e Ensino do 1ํㅡㄹ Ciclo do } \\
\text { Ensino Básico }\end{array}$ \\
\hline & & Ensino do $1^{\circ}$ Ciclo do Ensino Básico \\
\hline & & $\begin{array}{l}\text { Ensino do } 1^{\circ} \text { Ciclo do Ensino Básico e em Português } \\
\text { e História e Geografia no } 2^{\circ} \text { Ciclo do Ensino Básico }\end{array}$ \\
\hline & & $\begin{array}{l}\text { Ensino do } 1^{\circ} \text { Ciclo do Ensino Básico e em } \\
\text { Matemática e Ciências Naturais no } 2^{\circ} \text { Ciclo do } \\
\text { Ensino Básico }\end{array}$ \\
\hline
\end{tabular}

Fonte: Elaborado pelas pesquisadoras com base nos sites de IES públicas que habilitam para o $1^{\circ}$ CEB.

A formação docente para atuação no $1^{\circ}$ Ciclo do Ensino Básico, oferecida pelas universidades públicas, é de dupla habilitação, ou seja, dá a possibilidade ao formado de atuar em outra etapa além do ensino no 1ํㅡㄹ Ciclo do Ensino Básico. Dentre essas instituições, a metade oferece três especialidades de mestrado, ampliando a oferta de habilitação para o ensino no 1ํ Ciclo do Ensino Básico. Em relação aos institutos politécnicos, sete dos treze que formam professores para esse nível de ensino oferecem três especialidades de mestrado e somente um deles permite ao estudante cursar o mestrado com única habilitação. 
Para ingressar nos ciclos de estudos conducentes ao grau de mestre, o candidato deve ter domínio oral e escrito da língua portuguesa, bem como das regras necessária à argumentação coerente e crítica. As instituições de educação superior são as responsáveis pela avaliação do desempenho dos candidatos perante as condições estabelecidas pela legislação e têm autonomia para decidir a metodologia que utilizarão para obter o resultado. Quanto ao ingresso nas especialidades de mestrado que habilitem para docência no $1^{\circ}$ Ciclo do Ensino Básico, a legislação estabelece que "apenas podem candidatar-se ao ingresso a um ciclo de estudos conducentes ao grau de mestre numa das especialidades a que se referem os ํㅜ 1 a 5 do anexo ao presente decreto-lei os titulares da licenciatura em Educação Básica" (PORTUGAL, 2014, p. 2823).

O número de vagas para ingressos nos cursos de licenciatura e de mestrado é estabelecido anualmente pelas instituições de educação superior, que levam em consideração as manifestações da rede de escolas cooperantes e a disponibilidade de orientadores cooperantes, os limites estabelecidos pela Agência de Avaliação e Acreditação do Ensino Superior e aqueles estabelecidos para o funcionamento dos estabelecimentos, bem como as orientações gerais fixadas pela área de ensino superior. As instituições de educação superior que oferecem habilitação para a docência precisam celebrar acordos de cooperação com estabelecimentos escolares que ministrem educação pré-escolar e educação básica. Esses estabelecimentos recebem o nome de escolas cooperantes e têm como finalidade o desenvolvimento do componente de formação de iniciação à prática profissional, na qual se integra o ensino supervisionado. As escolas cooperantes e as instituições de ensino superior devem cumprir, conjuntamente, as indicações constantes no acordo de cooperação de forma a garantir o desenvolvimento da qualidade de ensino em ambos os estabelecimentos de educação (PORTUGAL, 2014).

A habilitação para atuação docente em Portugal sofreu importantes alterações pósBolonha. As modificações vão desde a criação dos ciclos de estudo e o aumento do grau acadêmico, passando a exigir mestrado para o exercício profissional, até a elaboração, pelos cursos superiores, de currículos que contemplem uma formação generalista (licenciatura) e profissionalizante (mestrado), baseada em componentes de formação que atendam os limites de créditos designados por lei. Se por um lado podemos entender a obrigatoriedade do grau de mestre como um fator de valorização profissional e aumento no tempo de formação, por outro, nos leva questionar se os pesos atribuídos a cada área formativa são suficientes para o desenvolvimento do aprofundamento teórico, da articulação entre teoria e prática e de posturas críticas e atuantes. O impacto de Bolonha nos cursos de formação docente é discutido por autores portugueses que nos ajudam a refletir sobre seus pontos positivos e negativos.

\section{Percepções de Autores PoRtugueses sobre formaçÃo doCENTE}

Para Leite (2012) ao reorganizar a formação inicial de professores em dois ciclos de formação (licenciatura e mestrado), oferecendo uma formação generalista na licenciatura e uma formação para o exercício da docência no mestrado, Portugal atende as orientações de Bolonha, mas retrocede ao abandonar a característica integradora que acontecia nos primeiros anos de formação. Segundo a autora, apesar do elevado nível acadêmico exigido para a habilitação profissional, o tempo destinado à formação inicial de professores não é muito maior que o estabelecido anteriormente à 
reforma e que a estrutura atual dificulta o contato progressivo com atividades docentes. Para a autora, a ampliação dos saberes e sua aplicação social no cotidiano educacional depende da socialização profissional, dificultada pelo modelo trazido por Bolonha que oferece poucas oportunidades de aprofundar conhecimentos educacionais e vivenciar situações reais relacionadas à diversidade e à complexidade no exercício da docência. Esse modelo de formação apregoado por Bolonha, para Leite (2014), oferece poucas oportunidades de reflexão de um quadro teórico fundamentado nos discursos acadêmicos e nas aprendizagens sociais. Para a autora, "os estudantes, futuros professores, deveriam ir vivenciando ao longo desta formação inicial experiências profissionais cada vez mais prolongadas e produtoras de reflexões sobre os efeitos que iam sendo gerados." (LEITE, 2014, p.15).

Tal composição generalista de formação tem gerado conflitos entre os autores portugueses. De acordo com Mouraz et al (2012), as discordâncias abrangem o fato desse modelo de formação dificultar o aprofundamento de conhecimentos científicos ou por conter exigências específicas no segundo ciclo de estudos (mestrado) que são incompatíveis com sua duração. No entanto, as autoras afirmam que a característica bietápica da formação não é refutada por todos, professores formadores e estudantes/futuros professores compreendem esse um modelo como "banda larga", que aumenta a empregabilidade e possibilita uma melhor adequação dos professores da educação básica, pois se mostra capaz de abrir possibilidades de atuação profissional que será aprofundada pelo mestrado. Já na visão de Reis e Camacho (2009), a duração dos ciclos de formação pode ser entendida como um ponto positivo do pacto, pois o processo educativo passou a centrar-se no estudante, levando em conta suas experiências e aprendizagens e aumentando o equilíbrio e a articulação entre atividade docente, tutoria e prática.

O Processo de Bolonha exigiu mudanças na formação de professores que resultaram na reorganização estrutural e pedagógica com tendências homogeneizadora tendo em vista a instituição de ciclos de estudos por graus acadêmicos, de unidades de créditos, da mobilidade, da organização dos estudos por horas de contato, de tutoria e de trabalho autônomo (FERREIRA, 2013). No entanto, Reis e Camacho (2009) afirmam que o pacto não tem a intencionalidade, com a concretização do EEES, de uniformizar o cariz formativo das instituições de ensino superior, os planos de estudo, a estrutura curricular ou o método de ensino e aprendizagem, mas de criar um quadro harmônico de forma a facilitar o reconhecimento dos graus acadêmicos. Nesse contexto, Vieira e Damião (2013) defendem o tronco comum na formação inicial de professores, pois acreditam que esta deve ter um caráter mais homogêneo. Para as autoras, os futuros professores dos anos iniciais precisam de conhecimentos basilares para criarem estrutura sólidas durante o percurso acadêmico, mas entendem que tal alinhamento curricular não afetaria o perfil de formação da IES.

A incorporação portuguesa das políticas defendidas em Bolonha pode ser justificada, segundo Leite (2012), pela possibilidade de uma formação mais flexível, que forneça ao estudante percursos acadêmicos diferenciados a partir das opções disciplinares dentro ou fora do curso escolhido e pela adesão à mudança de paradigma ao romper com a ideia tradicional de formação. No entanto, a autora também critica o fato da formação para o exercício da docência acontecer no mestrado, dificultando o desenvolvimento do perfil necessário para desempenhar a profissão em razão do curto tempo para a conclusão do curso. Tal preocupação ganha maior repercussão quando se trata de habilitação dupla simultânea, isto é, aquela que forma para atuação 
profissional em dois níveis de ensino, pois o tempo destinado a cada um deles não é suficiente para que as especialidades necessárias para atuação profissional sejam aprofundadas. A autora aponta ainda que a formação generalista oferecida na licenciatura desperta opiniões contrárias, pois pode, com já explicitado, levar ao entendimento da impossibilidade de preparação docente no curto prazo do mestrado, mas também pode constituir uma mais-valia para o estudante na medida em que possibilita uma visão ampla da situação educacional e uma maior consciência na escolha do nível de ensino que pretende atuar.

Já para Flores (2003), o Processo de Bolonha trouxe transformações que repercutiram nos sistemas educativos das sociedades competitivas e levaram à reflexão do que se espera da formação docente. A organização da formação inicial de professores em dois ciclos de estudos aspira que os estudantes pensem sobre a sua prática e que se desenvolvam profissionalmente enquanto aprendentes ao longo da vida. Segundo a autora, a sociedade sofre transformações que exigem a reformulação, a redefinição e a discussão sobre a formação de futuros docentes para atuação em escolas e salas de aula. De acordo com Leal e Leite (2017), as escolas estão inseridas em um contexto de instabilidade trazido pela pós-modernidade, em que o professor deve ser capaz de criar estratégias para se adequar a realidade posta e, para tanto, sua formação precisa estar pautada no desenvolvimento de "competências holísticas, plurais e multifacetadas, capazes de apoiar a gestão de novas situações que os cotidianos vão apresentando" (LEAL; LEITE, 2017, p.6).

Para Formosinho (2009) o dilema da formação está em como produzir conhecimento, incentivando a reflexão crítica, e, na mesma medida, promover as dimensões formativas da missão do professor. Isso porque a cultura das instituições de ensino superior está baseada na produção de conhecimento abstrato, voltada para a especialização disciplinar estrita, em detrimento da formação de professores como profissionais de desenvolvimento humano. O confronto entre formação generalista e especialista deve levar à discussão sobre qual é a especialização pretendida e ao fato de que, ao integrar essas duas dimensões, o ensino superior pode proporcionar uma formação de professores que atenda à demanda da sociedade.

De acordo com Leite (2012), dois discursos permeiam os debates sobre formação de professores entre autores portugueses. Um diz respeito às dimensões sociais do ato educativo e outro destina-se à preocupação com políticas educacionais direcionadas à qualidade do ensino e que garantam ao professor, por meio de sua formação, a aquisição de competências e a obtenção de conhecimentos, como a consciência crítica e a capacidade de dirimir problemas e de gerir contextos (European Association for Quality Assurance in Higher Education, 2006). No entanto, para o desenvolvimento de competências que facilitem lidar com a complexidade do cotidiano docente, segundo Leite e Fernandes (2013), a formação de professores deve extrapolar conteúdos técnicos ou científicos e possibilitar um maior contato com a profissão.

Leal e Leite (2017) afirmam que as posições da comunidade científica em relação às políticas de formação inicial de professores em Portugal não são unânimes, no entanto, de acordo com as autoras, a maior parte se posiciona por uma adesão condicional ao pacto, pois reconhecem que as mudanças atenderam às demandas do século XXI, mesmo criticando a diminuição de práticas que promovem a adequada socialização da profissão. A diversidade de opiniões sobre as transformações implementadas após Bolonha é identificada por Leal e Leite (2017) em dois outros posicionamentos. Um que 
defende a adesão incondicional às medidas decorrentes do processo por entender que promovem a autonomia e as competências pessoais e sociais dos estudantes, bem como possibilitam a flexibilidade na formação, oferecendo variedades de opções, incentivando uma aprendizagem ativa. E outro que rejeita as políticas estabelecidas por acreditar que elas levaram a um retrocesso na formação em razão da diminuição do tempo de efetiva formação para exercício da docência e a diminuição da socialização profissional. Formosinho (2009) aponta que a fundamentação teórica oferecida no ensino superior, além de dever formar professores reflexivos, atuantes, críticos e comprometidos, deve contribuir na valorização da profissão e dos profissionais e melhorar as práticas dos professores, bem como o contexto das escolas. Essa melhoria, de acordo com Leite (2012), Leal e Leite (2017), Nóvoa (2009), entre outros autores portugueses, depende da integração do ensino com o envolvimento dos estudantes na realidade do exercício da profissão docente, pois amplia a habilidade em lidar com situações sociais complexas que permeiam a educação.

Já Roldão (2006) aponta que descritores da profissionalidade docente tais como o reconhecimento social da especificidade da função associada à atividade; o saber específico indispensável ao seu desenvolvimento; o poder de decisão sobre a ação desenvolvida e consequente responsabilização social e pública pela mesma; e a pertença ao corpo de pares legitimados pelo seu saber são indispensáveis no contexto de formação de professores a partir de Bolonha, a fim de diminuir a tensão entre a natureza da função docente e do saber necessário ao seu desempenho.

As transformações sociais e as relações interpessoais levaram à necessidade de se repensar o currículo da formação inicial docente, pois é na atuação profissional que o professor constata a disparidade entre sua trajetória formativa e a realidade encontrada. No entanto, a mudança no modelo formativo, de acordo com Formosinho (2009), levou a uma formação mais teórica e distanciada das preocupações vivenciadas na atuação profissional. O autor aponta que essa transformação, ao fortalecer o componente intelectual e desconsiderar aspectos relacionais e morais, afeta características como autonomia e cooperação, necessárias para a construção de uma escola multicultural e inclusiva.

Para Esteve (1999), a atuação docente não se restringe somente ao domínio cognitivo. Além do domínio do conteúdo a ser ministrado, exige-se que o professor seja um facilitador da aprendizagem, que atue de forma a contribuir com o equilíbrio psicológico e afetivo dos alunos, que se preocupe com a interação social deles e que consiga atender às demandas de uma turma diversificada e heterogênea não apenas cognitivamente, mas social e culturalmente. Dessa forma, a profissão docente requer uma certa autonomia, compreensão dos processos educacionais e conhecimento culturais e pedagógicos (WOODS,1999).

As mudanças significativas impostas à formação inicial de professores em Portugal levaram à preparação do futuro professor para atender às expectativas da sociedade atual, mesmo que essas mudanças, conforme nos lembra Esteve (1999), exijam estruturas curriculares que negligenciem o estudo das humanidades e transformem o ensino em um sistema que atenda a necessidades econômicas e profissionais do mercado. Preconiza-se uma escola humanista, que atenda às necessidades individuais e coletivas, contudo, de acordo com Cavaco (1999), a formação está voltada para a satisfação das aspirações econômico-sociais e o encaminhamento do profissional docente. 
Para Mesquita e Roldão (2017), a formação inicial de professores é uma preparação formal oferecida por instituições de ensino na qual o estudante assimilará conhecimentos pedagógicos e competências profissionais com base no modelo de formação oferecido. As autoras defendem que o conhecimento adquirido deve ser contextualizado e construído ao longo da vida, pois para elas a formação é um processo que se inicia, mas não se finaliza. No entanto, o Processo de Bolonha além de reforçar o dualismo entre formação científica e pedagógica, exigiu a organização sequencial, embasada nas orientações legais quanto às componentes de formação necessárias e à designação de créditos destinadas a cada uma delas. Para reverter a perda de prestígio profissional, mesmo com a exigência do mestrado, a instituições de ensino superior passaram a favorecer uma educação e formação vocacional, dando protagonismo à racionalidade técnico-instrumental no processo formativo de professores (LIMA, 2016).

A partir desse panorama, Nóvoa (2015) nos convida a refletir sobre as tendências formativas da universidade, principalmente pós-Bolonha, e aponta duas linhas largamente debatidas: uma relacionada à ideia tradicional de formação, na qual entende a universidade como instituição social dissociada do valor comercial, e outra, ao contrário, que atribui valor econômico relacionado à instrução profissional e à atuação no mercado de trabalho. $O$ autor alerta sobre a ideologia de modernização que invadiu a universidade e estabeleceu seu valor econômico. Essa ideologia, segundo ele, tem como enfoque a excelência, o empreendedorismo, a empregabilidade e a europeização. $O$ avanço na formação profissional universitária depende, segundo Nóvoa (2017), da construção de um lugar institucional que alie os variados contextos que caracterizam a profissão. A universidade é decisiva e não pode ser substituída na formação, então não se trata de uma nova organização institucional, mas o estabelecimento de vínculos externos que fortaleçam a formação, que por sua natureza lida com incertezas e situações imprevistas. A universidade e as escolas precisam dialogar com o objetivo de integrar o espaço formativo e o espaço profissional, valorizando as experiências e os conhecimentos de ambas instituições.

$\mathrm{O}$ ato educativo e a profissão docente apresentam natureza complexa, pois "a docência é, ao mesmo tempo, uma actividade intelectual e uma atividade técnica; uma actividade moral e uma atividade relacional (...) tem, na acção quotidiana, dimensões técnicas, mas também dimensões artesanais, dimensões intelectuais, mas também dimensões artísticas" (FORMOSINHO, 2009, p. 91). No entanto, o autor salienta que o processo de academização pode reduzir o papel da docência, transformando-o em uma atividade unicamente intelectual, esquecendo-se que, além de ser um especialista em uma área do saber, o professor também exerce uma atividade de serviço, ou seja, sua atuação está ligada ao desenvolvimento humano. Por outro lado, o autor reconhece que a exigência de ensino superior promove a formação de professores mais fundamentados, críticos e reflexivos sobre os mais variados contextos. Os benefícios trazidos pela formação inicial de professores possibilitam, além de "uma fundamentação teórica mais sólida da ação educativa, a valorização do estatuto da profissão docente, mais investigação em vários domínios das ciências da educação" (FORMOSINHO, 2009, p. 84).

O conhecimento de realidades sociais e de culturas diversas define a educação na atualidade e leva a impossibilidade de uma formação de professores que se feche à sociedade. A fim de atender as demandas impostas pela sociedade, listas de competências para o trabalho docente tornaram-se corriqueiras, mas se mostraram 
ineficientes em demonstrar a real complexidade da profissão, bem com a finalidade da formação. O discurso das competências no processo formativo dificulta o amplo entendimento do que é ser professor (NÓVOA, 2017). Já Leitão e Alarcão (2006) apresentam um olhar diferenciado sobre o papel das competências na formação inicial de professores, pois entendem que a profissionalização baseada em competências profissionais é capaz de promover o desenvolvimento social e humano de forma a mobilizar os futuros professores, por meio de sua ação educativa, à constituição de uma sociedade mais humana e justa.

Podemos dizer que a formação de professores em Portugal tem enfrentado tensões e conflitos entre os autores portugueses, pois se, por um lado, deve-se atender aos compromissos firmados com a assinatura da Declaração de Bolonha e às exigências impostas pelo mundo globalizado, por outro, deve-se empenhar na superação dos desafios intrínsecos à profissão, que depende tanto de solidez de conteúdos para a docência, como do desenvolvimento de competências para promover o sucesso escolar na instituição educacional que o futuro professor vier integrar.

\section{CONSIDERAÇÕES FINAIS}

Os cursos de formação docente para os anos iniciais em Portugal tiveram seus currículos modificados pelo processo de Bolonha e, por isso, destinam-se ao desenvolvimento das competências, ao aumento da mobilidade, à flexibilidade de percursos formativos, à abertura de possibilidades profissionais e de formação ao longo da vida. Os objetivos de formação propostos pelos cursos geraram mudanças nos papéis dos estudantes e dos professores, levando a uma nova discussão sobre a identidade profissional.

A análise das alterações curriculares para a formação inicial de professores de $1^{\circ}$ ciclo reforça o entendimento apontado por Machado (2009) de que o currículo não é neutro e não pode ser percebido como um ato descolado da sociedade da qual faz parte. Como salienta Rasco (2013, p. 415), "Europeizar a educação, especialmente a educação superior, atualmente pressupõe submetê-la a uma estrutura normativa rígida e a uma modificação profunda de seus conteúdos, aproximando-as das necessidades do mercado e da produtividade".

Autores portugueses discutem as mudanças na formação docente implementadas a partir das orientações de Bolonha para o ensino superior apontando suas fragilidades e potencialidades. Os posicionamentos sobre a estrutura e a organização atuais dos cursos abordam desde sua submissão ao sistema econômico até a preocupação com a produção de conhecimentos críticos essenciais à construção do perfil profissional. Sem adotar uma visão maniqueísta, estudiosos da área apresentam opiniões divergentes e encontram argumentos tanto para apoiar quanto para refutar medidas educativas que podem ser consideradas por uns, benéficas e, por outros, maléficas. Essa percepção se torna evidente, por exemplo, quanto às consequências da formação bietápica na articulação entre teoria e prática, na duração dos ciclos e na socialização da profissão.

A mudança de paradigma trazida por Bolonha prevê uma formação superior voltada para o desenvolvimento de competências. Se por um lado essa transformação pode ser entendida como consequência do sistema de créditos e da necessidade de mobilidade dos estudantes, por outro, é vista como uma política para entrada de 
diplomados no mercado de trabalho. Tal modelo provocou uma nova formação universitária centrada na aquisição de competências e, por conseguinte, uma transformação metodológica, curricular, organizacional e de estratégias de ensino superior (MENDES, 2010).

Em contrapartida de uma formação humanística, o atual modelo de formação docente em Portugal tem se voltado, cada vez mais, aos atendimentos das demandas do mercado. Isso porque as sociedades tem sido influenciadas por interesses externos, de natureza econômica e cultural, em que "os grandes fluxos econômicos e os interesses que escondem por trás deles, bem como as novas categorias de raça, gênero, geração, etnia e cultura reconfiguram e determinam não só as posições do sujeito, mas também, a relação das instituições com o todo social" (GOERGEN, 2010, p.63).

Goergen (2010) ressalta o processo de revisão pelo qual o conceito de comunidade humana atravessa em dois cenários: a globalização, em que acontecimentos internacionais influenciam ou determinam o curso da economia e da ciência regionais; e os movimentos culturais representados pelos desejos, ambições e pretensões das comunidades locais. Nesse cenário, a produção de conhecimento atribuída ao ensino superior tem se voltado à construção de saberes e tecnologias que atendam o sistema de produção (CENCl; DALBOSCO, 2016).

A transformação do ensino superior europeu atribuiu novos papéis a estudantes e professores, contudo, o ato educativo não deve ser anulado em razão de tais mudanças. Para que o estudante possa desempenhar bem um papel mais autônomo em sua formação, precisará que lhe seja fornecido meios para que desenvolva e adquira conhecimentos, habilidades e competências. Nesse sentido, faz-se necessária uma reflexão sobre o modelo de formação docente decorrente do Processo de Bolonha, pois a atual formação inicial não começa com o ingresso na educação superior. A estrutura de formação docente de Portugal, de acordo com Leite (2012), não é muito maior que a anterior e, apesar de conceder um grau acadêmico maior aos professores, dificulta a formação de um currículo que possibilite a ampliação do contato com os dilemas reais da profissão. O currículo proposto leva a questionamentos sobre uma maior qualidade na formação docente desse modelo, objetivo pretendido pelos discursos políticos e acadêmicos na atual sociedade.

Concordamos com Nussbaum (2015) quando diz que a importância do investimento na ciência e na educação técnica não se deve ignorar o pensamento crítico, a capacidade de agir como cidadão do mundo e a empatia, competências ligadas às humanidades e às artes, que também são essenciais para o progresso e bem-estar das democracias. Para a autora, a avaliação do sistema educacional deve levar em consideração a maneira como os jovens são preparados para viverem numa sociedade composta por pessoas diferentes no que se refere a religião ou etnia, gênero ou orientação sexual, etc.

\section{REFERÊNCIAS}

ALMEIDA, Sílvia de; FARIA, Ercília. Instituições de formação e classificações dos docentes da educação pré-escolar e dos ensinos básico e secundário. In: Conselho Nacional de Educação. Formação Inicial de Professores. Universidade do Algarve, 2015, p. 22-84.

CAVACO, Maria Helena. Ofício do professor: o tempo e as mudanças. In: NÓVOA, António. Profissão professor, Porto: Porto Editora, 1999, p. 155-191. 
CENCI, Angelo Vitório; DALBOSCO, Claudio Almir. Educação Superior e formação humana: um diálogo com Pedro Goergen. Filosofia e Educação, Campinas/SP, v.8, n.2, p. 141-167, jun./set. 2016. Disponível em: https://periodicos.sbu.unicamp.br/ojs/index.php/rfe/article/view/8647118/14056. Acesso em: 19 mar. 2019.

DECLARAÇÃO DE BOLONHA. 1999. Disponível em: http://www.abc.org.br/wpcontent/uploads/2009/09/www.ufabc .edu .br images stories pdfs declaracaodebolonhaportu gues.pdf.Acesso em: 30 ago. 2017.

EUROPEAN ASSOCIATION FOR QUALITY ASSURANCE IN HIGHER EDUCATION (ENQA).Disponível em: https://enqa.eu. Acesso em: 19 maio 2019.

ESTEVE, João M. Mudanças sociais e função docente. In: NÓVOA, António. Profissão professor, Porto: Porto Editora, 1999, p. 93-124.

FERREIRA, Carlos Alberto Alves. Uma abordagem à avaliação das aprendizagens na formação de professores no contexto de Bolonha. Avaliação, Campinas; Sorocaba/SP, v.18, n. 3, p. 685-707, nov. 2013. Disponível em: http://www.scielo.br/pdf/aval/v18n3/09.pdf. Acesso em: 14 jan. 2019.

FORMOSINHO, João. A academização da formação de professores. In: FORMOSINHO, João (Org.). Formação de professores: aprendizagem profissional e acção docente. Porto: Porto editora, 2009. p.7392.

GALEGO, Carla. Políticas educativas e ensino superior. Análise da internacionalização no contexto de trabalho da profissão acadêmica em Portugal. Rev. Inter. Educ. Sup., Campinas/SP, v. 2, n. 1, p. 10-30, jan./abr. 2016. Disponível em: https://periodicos.sbu.unicamp.br/ojs/index.php/riesup/article/view/8650535/16746. Acesso em: 11 maio 2018.

GOERGEN, Pedro. Educação instrumental e formação cidadã: observações críticas sobre a pertinência social da universidade. Educar, Curitiba/PR, n. 37, p. 59-76, maio/ago. 2010. Disponível em: http://www.scielo.br/pdf/er/n37/a05n37.pdf. Acesso em: 30 nov. 2018.

LEAL, Ana Rita; LEITE, Carlinda. Políticas da formação inicial de professores, em Portugal, decorrentes de Bolonha: posições da comunidade científica. Interritórios. Universidade Federal de Pernambuco. Caruaru/PE, v.3, n.4, 2017. p.5-30. Disponível em:

https://www.researchgate.net/publication/322747056 Politicas da Formacao Inicial de Profe ssores em Portugal Decorrentes de Bolonha posicoes da comunidade cientifica. Acesso em: 15 jan. 2019.

LEITE, Carlinda. (2012). A formação inicial de professores no quadro dos compromissos de Bolonha contributos para uma reflexão sobre o que foi instituído em Portugal. Revista Brasileira de Pesquisa sobre Formação Docente. Belo Horizonte/MG, v.4, n.7, p.10-18. jul./dez. 2012. Disponível em http://formacaodocente.autenticaeditora.com.br. Acesso em: 20 maio 2018.

LEITE, Carlinda. Políticas de formação de professores do ensino básico em Portugal: uma análise focada no exercício da profissão. Revista Educação e Cultura Contemporânea, v. 11, n. 26, 2014,

LEITE, Carlinda; FERNANDES, Preciosa. A formação inicial de professores em Portugal: para uma reflexão sobre o modelo decorrente do Processo de Bolonha. In LOPES, Amélia (Org.). Formação inicial de professores e de enfermeiros: identidades e ambientes. Lisboa: Mais Leituras, 2013, p. 55-67.

LEITÃO, Álvaro; ALARCÃO, Isabel. Para uma nova cultura profissional: uma abordagem da complexidade na formação inicial de professores do 1ํ CEB. Revista Portuguesa de Educação, Minho, v. 2, n.19, 2006, p. 51-84. Disponível em: http:/www.scielo.mec.pt/pdt/rpe/v19n2/v19n2a04.pdf. Acesso em: 10 fev. 2019.

LIMA, Licínio C. Sobre a educação cultural e ético-política dos professores. Educar em Revista, Curitiba, Brasil, n. 61, p. 143-156, jul./set. 2016. Disponível em: https://revistas.ufpr.br/educar/article/view/46864/29228. Acesso em: 30 mar. 2019.

MACHADO, Liliane Campos. Formação, saberes e práticas de formadores: um estudo em cursos de licenciatura em história e pedagogia. 2009. 292f. Tese (doutorado) - Universidade Federal de Uberlândia, MG, 2009. Disponível em: https://repositorio.ufu.br/bitstream/123456789/13618/1/T\%20liliane.pdf. Acesso em: 22 jun. 2018.

MARTINS, Isabel. Painel: os acordos de Bolonha e os desafios da formação inicial de professores. Depoimento de Isabel Martins. Revista de Educação, Lisboa, v.15, n. 1, p.5-10, 2006. 
MENDES, Bruno Alexandre Marques Monteiro. Bolonha: um novo paradigma, uma nova aprendizagem? - O que nos dizem os Relatórios de Concretização do Processo de Bolonha. 2010. 273f. Dissertação (Mestrado) - Universidade do Porto, Porto, 2010.

MESQUITA, Elza; ROLDÃO, Maria do Céu. Formação inicial de professores: a supervisão pedagógica no âmbito do processo de Bolonha. Lisboa: Edições Símbalo, 2017.

MOURAZ, Ana; LEITE, Carlinda; FERNANDES, Preciosa. A formação inicial de professores em Portugal decorrente do processo de Bolonha: uma análise a partir do "olhar" de professores e de estudantes. Revista portuguesa de pedagogia, v. 2, n. 46, p. 189-209, 2012. Disponível em: https://impactum-journals.uc.pt/rppedagogia/article/view/1744/1120. Acesso em: 12 abr. 2018.

NÓVOA, António. Para una formación de profesores construida dentro de la profesión. Revista de Educación, n. 350, p. 203 -218. set./dez. 2009. Disponível em: http://www.revistaeducacion.mec.es/re350/re350 09.pdf. Acesso em: 24 abr. 2018.

NÓVOA, António. Firmar a posição como professor, afirmar a profissão docente. Cadernos de pesquisa, v. 47, n.166, p. 1106-1133, out./dez. 2017. Disponível em: http:/www.scielo.br/pdf/cp/v47n166/1980-5314cp-47-166-1106.pdf. Acesso em: 30 mar. 2019.

NUSSBAUM, Martha. Sem fins lucrativos: por que a democracia precisa das humanidades. São Paulo: WMF Martins Fontes, 2015.

PEREIRA, Elisabete Monteiro de Aguiar. O Processo de Bolonha e a formação do espaço europeu de educação superior - EEES: 10 anos da reforma universitária europeia. In: PEREIRA, Elisabete Monteiro de Aguiar; ALMEIDA, Maria de Lourdes Pinto de. Reforma universitária e a construção do espaço europeu de educação superior: análise de uma década do Processo de Bolonha. Campinas, SP: Mercado das letras, 2011. p. 17-37.

PORTUGAL.. Lei oㅜ 49/2005, de 30 de agosto de 2005. Diário da República, Lisboa, 2005. Disponível em: https://dre.pt/application/file/245260. Acesso em: 13 maio 2018.

PORTUGAL. Decreto-Lei n 74/2006, de 24 de março de 2006. Diário da República, Lisboa. Disponível em: https://dre.pt/application/file/671482. Acesso em: 15 maio 2018.

PORTUGAL. Decreto-Lei no 62/2007, de 10 de setembro de 2007. Regime Jurídico das Instituições de Ensino Superior, 2007. Disponível em: <http://www.mctes.pt/docs/ficheiros/RJIES.pdf>. Acesso em: 17 maio 2018.

PORTUGAL Lei oㅜ 79/2014, de 14 de maio de 2014. Diário da República, Lisboa, 2014. Disponível em: https://dre.pt/application/conteudo/25344769. Acesso em: 18 maio 2018.

RASCO, José Félix Ângulo. A educação e o currículo no espaço europeu: internacionalizar ou globalizar? In: SACRISTÁN, José Gimeno. Saberes e incertezas sobre o currículo. Porto Alegre: Penso, 2013. p. 403-418.

REIS, Pedro Rocha dos; CAMACHO, George. A avaliação da concretização do processo de Bolonha numa instituição de ensino superior portuguesa. Revista Española de Educación Comparada. v. 15, p. 41-59, 2009.

ROLDÃO, Maria do Céu. Bolonha e a profissionalidade docente: perder ou ganhar uma oportunidade histórica? Revista de Educação, Lisboa, v.15, n. 1, p.37-56, 2006.

VIEIRA, Mônica Duarte; DAMIÃO, Maria Helena. Formação Inicial de Professores do $1^{\circ}$ Ciclo do Ensino Básico: Requisitos de Ingresso, Planos de Estudos e Perfis de Docência. Revista Portuguesa de Pedagogia, ano 47-I, p. 127-156, 2013. Disponível em: http://www.sc.ehu.es/sfwseec/reec/reec15/reec1503.pdf. Acesso em: 15 maio 2019.

WOODS, Peter. Aspectos da criatividade do professor. In: NÓVOA, António. Profissão professor, Porto: Porto Editora, 1999, p. 125-154.

Data da submissão: 21/06/2019

Data da aprovação: 30/11/2019 